\title{
Nationwide survey on the use of local antibiotics during anterior cruciate ligament reconstruction in Norway
}

Monica Alessandria Sailer ( $\square$ monica_sailer@yahoo.no)

Akershus Universitetssykehus HF https://orcid.org/0000-0002-1022-7845

Inge Skråmm

Akershus Universitetssykehus HF

Einar Andreas Sivertsen

Lovisenberg Diakonale Sykehus AS

Stein Håkon Lygre

Haukeland Universitetssjukehus

Asbjørn Årøen

Akershus Universitetssykehus HF

Research note

Keywords: Anterior cruciate ligament reconstruction, Vancomycin, infection

Posted Date: July 28th, 2020

DOI: https://doi.org/10.21203/rs.2.24413/v2

License: (c) (i) This work is licensed under a Creative Commons Attribution 4.0 International License.

Read Full License 
The authors have withdrawn this preprint from Research Square 